\title{
'[T]his is eating your greens, this is doing your homework': Writing and Rehearsing a Full-Length Stand-Up Show
}

Andy de la Tour, a prominent alternative comedian, acknowledges that he never spent much time reflecting on the creative processes behind his art: 'I mean if I'm honest, I don't think I've ever - ever had - a kind of, as it were, serious conversation or discussion about how you do this stuff... I'm not sure anybody did, to be honest'. ${ }^{1}$ The fact that such a key figure as de la Tour has no recollection of discussing the methodology of stand-up - at a time when the possibilities of the form were being actively explored - indicates just how much the processes comedians use to create their stage acts are shrouded in mystery. Indeed, most comics have to learn for themselves exactly how to generate material and prepare it for performance, usually without any formal training or outside help.

More recently, comedians have begun to shed light on the methods they use by discussing them more publicly. Sometimes this occurs in comedians' autobiographies, like Steve Martin's Born Standing Up. ${ }^{2}$ Similarly, Stewart Lee has written two books in which transcripts of his full-length shows are presented along with introductory commentaries explaining the context within which he created them, and copious footnotes which explain the thinking behind many of the gags and routines. ${ }^{3}$

Since 2012, Stuart Goldsmith has been producing The Comedian's Comedian Podcast, in which he interviews comics, normally in front of a live audience, about how they work. In the first episode, he explains his rationale:

I've been doing it for about seven years and...I just realised that I was working full-time in a profession for which I'd received no training at all. So my initial idea for this show...it was just going to be a masterclass where I would invite comedians who I love and think are great and think I can learn something from and...organise almost a gig whereby they could talk to other comics of my level...and tell us how they do it...But I approached a couple of people and they all said similar things, which was that 'God no, I don't have any methodology...' And I just sort of thought, 'Although they might think that, that can't really be true, I mean, everyone has a way of doing things that to them seems really obvious and not worth mentioning. ${ }^{4}$

On the one hand, Goldsmith's explanation shows evidence of an emerging serious interest in the methodologies of stand-up - but on the other it also acknowledges that some comedians are still resistant to revealing or even reflecting on how they work.

There has been a small amount of academic work on stand-up methodology, notably a recent article by Christopher Molineux, in which he uses interviews conducted with 31 comedians from various countries to discuss their writing methods and, more particularly, the different ways in which they document ideas for material. Molineux reveals that standup comedians rarely generate a fixed, verbatim script. The notes they generate tend to lack 
the clarity and completeness of a play text, and it may be that only the comedian himself or herself will be able to fully interpret them. This means that, as Molineux notes, 'the selfdocumentation of the stand-up comedian, being cryptic and devoid of the qualities sought in archive material, is likely to be perceived as having little value which puts it at some risk of being disregarded or destroyed. ${ }^{5}$

It is precisely to prevent such material from disappearing that we established the British Stand-Up Comedy Archive (BSUCA) at the University of Kent in 2013, following the donation of the personal archive of the late Linda Smith. As BSUCA's website notes, it exists 'to celebrate, preserve, and provide access to the archives and records of British stand-up comedy and comedians. ${ }^{6}$ Although it is still in its early stages, the archive is already an eclectic collection, including unpublished recordings, interviews, scripts, set lists, photographs, leaflets, posters, props, costume items, press reviews, business records, bookings diaries, contracts, and personal correspondence.

In this article, I will draw on such materials to examine the creative processes used in standup comedy, but my central focus will be an analysis of my own working methods. I started performing stand-up in the 1980s and worked as a professional comedian, mainly in provincial comedy clubs, until 1997 when I became a university lecturer. Even then, I still did the occasional circuit gig before notionally giving it up in 1999. However, stand-up has been a hard habit to kick, and I have found myself performing fairly regularly ever since. Notably, in 2006 I did a full-length stand-up show called Saint Pancreas, about raising two children with type 1 diabetes, which led to versions of the show being performed for diabetes events in the UK and the USA over the next few years.

This article will particularly focus on a new full-length stand-up show entitled Break a Leg, which I performed at the Gulbenkian, Canterbury, in December 2015. ${ }^{7}$ Earlier that year I had broken my hip, and the show was about my accident, the subsequent operation, and the long and painful recovery period, touching on such unlikely comic themes as ageing and mortality. Given that I was simultaneously creating my own stand-up show and working with materials in BSUCA which shed light on the varied creative processes which comedians use to construct their acts, I decided to bring these two halves together to form a practiceas-research project.

The idea was to systematically document the creative process, in order to examine from the inside the processes by which stand-up comedy is made, and also to consider the particular issues that arise from documenting this specific field of performance. In his book Practice as Research in the Arts, Robin Nelson defines three types of knowledge in relation to PaR, these being 'know-that' (knowledge and analysis of performance from the outside, in the form of, for example, spectatorship studies and conceptual frameworks), 'know-how' (the 
performer's tacit, experiential knowledge of the nuts and bolts of making performance), and 'know-what' (this tacit, experiential knowledge 'made explicit through critical reflection'). ${ }^{8}$

In recent years there has been an increase in academic interest in stand-up, but the focus has tended to be firmly on know-that. For example, a special issue of the journal Comedy Studies sought to address 'the lack of literature on "how" to analyse stand-up comedy' ${ }^{9}$ by presenting a series of articles which examined the same Joan Rivers routine, picking out different themes such as Jewishness or gender, or using different theoretical frames such as semiotics or humour theory. ${ }^{10}$

The Molineux article aside, there has been little appetite among academics to investigate the working methods of stand-up comedy, and even the comedians themselves may be completely unaware of the experiential, embodied knowledge they possess. As Goldsmith recalled, the comedians he initially asked about his podcast claimed 'I don't have any methodology', but he reasoned that this was because it seemed to them that their working methods were 'really obvious and not worth mentioning'. This tacit knowledge only becomes explicit through critical reflection, and Goldsmith's podcast, along with books like Martin's and Lee's, have opened up a space for such reflection - thus allowing know-how to be transformed into know-what.

Nelson recommends that those engaging in PaR should 'think through in advance the variety of documentary strategies in which it might be helpful to engage'. ${ }^{11}$ The most important method used to document my processes was that, in addition to carefully storing any materials used in the creation of the show, I also recorded a podcast called Breaking a Leg. This was made up of 21 episodes, released between August 2015 and February 2016 via iTunes and Jellycast. I chose podcasting as a method of documentation because it reflected the fact that stand-up is largely an oral medium, with spoken language at its core. In addition to this, I recorded most episodes alone in a room. This closely mirrored the rehearsal process for the show, which would become a particular focus of the project.

What Martin's and Lee's books have in common with Goldsmith's podcast is that all of them offer retrospective reflection on working methods. In each case, the comedians are looking back on work they have already done, and reflecting on it with hindsight. The idea of the Breaking a Leg podcast was to record and reflect on my creative processes whilst actively engaged in them, during the process of preparing my show. Most of the episodes were released before I actually performed it.

This article will draw on material from my podcast in order to uncover knowledge from deep inside the creative process, taking a comedian's-eye view of it from the period when the show was actually being made. This will allow me to explore both practical and emotional aspects of stand-up methodology, focusing particularly on writing and rehearsal. 


\section{Writing stand-up comedy}

Matthew Reason has questioned the impulse to document live performance, arguing that while it is often seen as 'fundamentally ephemeral', actually 'the idea that every performance of a production is different' can be challenged by reference to specific examples. ${ }^{12}$ The fact that The Mousetrap has run for over 200,000 performances 'suggests that live performance is evidently repeatable', and with big budget international musicals, 'performance becomes a commodity that is repeated as exactly as possible not just night after night but year after year regardless of cast changes, the employment of new director or the restaging in new venues. $^{13}$

Nonetheless, it is the perception of the ephemerality of live performance which leads to the impulse to document it: '[I]t must be consciously documented if it not to disappear, with the primary preoccupation not the creation of new art but ensuring the documentation of existing art.' The problem is that performance is inherently difficult to document: 'Given the transience of live art, the live performance archive or museum is more problematic, as it by definition cannot contain actual performances - the thing itself is always absent.' As a result, archives contain materials relating to performance in some way, in lieu of the actual performance. These can include 'material detailing the processes of creation, production and reception.' 14

Reason also acknowledges that there may be more practical motivations to document performance other than the simple desire to stop it from disappearing into the ether, and cites the 'extreme pragmatism' of groups like Forced Entertainment. For them 'documentation is the logical response to the need to make the work available to people who want to know about it and see it', and they use it to promote their work as part of their overall marketing strategy. ${ }^{15}$

Much of the material which BSUCA has collected relates to the creation, production and reception of stand-up comedy, particularly set lists, various forms of performance script, and comedians' own unpublished audio recordings of their work. I would argue that the very existence of these materials is motivated by extreme pragmatism, because it was this that motivated the stand-ups to make and keep them. However, unlike Forced Entertainment, comedians use documentation not to market the work, but as an important part of the making process.

Although The Mousetrap and big budget musicals may be highly 'repeatable', stand-up is genuinely transitory. As Molineux notes, 'Unlike an actor in a play, the stand-up comedian habitually chops and changes their work at will in the preparation stage and in performance. ${ }^{16}$ Moreover, as I have previously argued, stand-up is 'firmly and 
conspicuously rooted in the present tense', with the comedian able to weave the immediate circumstances of the show into its very fabric, interacting with individual punters or the audience as a whole and commenting on anything unexpected that may happen. ${ }^{17}$ It is true that the material of the show can be carried forward from show to show, sometimes over a period of years, but this material should not be viewed as a text in its own right but rather as half of a quasi-conversation with the audience, in which their responses form the other half.

It is not just the less predictable responses, notably heckling, that make each show different from the previous one, but also the changes in the frequency and nature of the laughter and applause. The comedian's job is not simply to deliver the material, but rather to use it together with any improvised elements - to create a given response in the audience. Provoking laughter is a defining feature of stand-up comedy, and the precise nature of audience reactions will vary from show to show. This means that stand-up is, as Mark Thomas puts it, 'an encounter not a recital.'18

As Molineux notes, the 'scripts' comedians produce can take a variety of forms, including 'writing in notebooks or on scraps of paper, napkins, coasters or arms and hands; typing on phones, tablets and laptops; and voice recording on phones', although these initial jottings will often be transferred to a 'permanent archive'. However, even here the material is 'not intended to act as an unalterable script for what was to perform on stage. ${ }^{19}$

The relationship between the words written down on napkin, hand or page and the words actually spoken on the stage will differ from comedian to comedian. For example, BSUCA contains performance notes written by the late Linda Smith as part of the preparation for a gig at Downstairs at the King's Head in Crouch End, London, on 18 April 2001. These are word processed with handwritten additions, and look more like a set list than a formal script. One note simply reads:

Art how long - minimum. ${ }^{20}$

An audio recording of the King's Head show reveals how this gag worked in performance:

Art's a tricky business, isn't it though, really? I never know, I'm a bit ha- on happier ground with modern art. 'Cos you just know it's rubbish, you don't have to - wonder about it, you think, 'Oh - it's a, it's a pile of rubbish, innit, that's all right. Got no, gives me no worries.' But traditional art, in a gallery, is more problematic. 'Cos you, you see, you see the painting then, you think, 'How long - d'you have to wait in front of each painting? [laughter] What is - the minimum amount of time, without looking like an ignorant peasant who doesn't know what they're looking at? [laughter] ${ }^{21}$

Here, the words Smith has written offer nothing more than a reminder to herself of which gag to do at this point in the act. The material remains cryptic on the page, not really 
yielding any idea of the comic point of the joke - an observational gag about the anxiety of not knowing the proper etiquette to adopt in art galleries - which only becomes clear when it is performed. There is a major gulf between the four words inked onto the page and the 105 words actually spoken in performance.

By contrast, Andy de la Tour wrote his ideas in prose form, noting the ideas down so they could later be refined when performed:

I wrote my stuff, and I've got pages and pages of this, pages. I actually wrote it - in a grammatically correct way, as text...And so all the material, all the routines I did, have all got behind them a written text. Which if you read it, they're hugely unfunny, these pieces of written text, but...as I'm writing I can see where the laughs should be. And those pages of text would then get, in performance, would get distilled down. But it would start from me sitting at a typewriter or with a notepad, writing it as prose...and I never thought of perhaps doing it any other way.... It was just me formulating the train of thought, to get there. ${ }^{22}$

In the handwritten notes he has deposited in BSUCA the material makes sense on the page. The point of the joke comes across, even if the reader has not seen the routine being performed. For example, one of his signature early routines satirised media coverage of the Troubles in Northern Ireland, which he argued was ridiculous because of the broadcasters' refusal to acknowledge that this was a war situation. To make the point, he imagines the Second World War being reported in the same style as radio news broadcasts of his own time reporting terrorist incidents in Northern Ireland.

Comparing the written notes with the routine as performed, there are differences in the setups, punchlines and the running order of the gags. Nonetheless, all of the gags make sense on the page and some anticipate almost exactly how they would be performed. One joke is expressed in the notes like this:

Meanwhile, earlier in the day, two bombs went off in the predominantly Japanese towns of Hiroshima and Nagasaki. No one has yet claimed responsibility. ${ }^{23}$

De la Tour performs the gag almost word for word in an Alternative Cabaret show at the Elgin, Ladbroke Grove on 27 March 1980:

Ah, a newsflash. Two bombs went off today in the predominantly Japanese towns of Hiroshima and Nagasaki. [laughter, 4 seconds] No-one has yet claimed responsibility. [laughter, 3 seconds] ${ }^{24}$

In both cases, the satirical point of the joke is equally clear, resting on the incongruous transposition of key phrases used in the coverage of Northern Ireland ('predominantly Catholic' areas, the IRA 'claimed responsibility') to a key event in World War Two. 


\section{Writing Break a Leg: initial ideas}

Molineux identifies three modes of writing that comedians use. Firstly, there are 'new material sessions', which involve 'time set aside specifically to create and document new material'. ${ }^{25}$ In Molineux's survey, only $13 \%$ of comedians said they regularly did this, and Jo Brand is a good example of a comedian who avoids this approach: 'I very rarely sit down at my computer and write for hours on end, because I simply don't have the time (or the inclination) to do this. ${ }^{26}$ Secondly, there is 'stage writing', which is 'material that was initially improvised by the performer during the course of a performance'. Thirdly, there is 'unscheduled writing', in which 'comedy ideas having the potential to be used in performance appeared during the course of the comedian's daily life. ${ }^{27}$

I have never been able to produce good quality material by setting time aside to create it, having to rely instead on stage writing or - much more frequently - unscheduled writing. Break a Leg was no exception, as all the key jokes and routines started with inspiration arriving unbidden and unexpected. That said, as I noted in the podcast, there were particular times in which ideas were more likely to arrive, particularly the hours I spent in the swimming pool, initially water walking and later swimming as part of the physiotherapy after my operation:

[S]wimming is a great time for private thought, because you can't really have a conversation with somebody when you're piling up and down the length of a swimming pool. So yeah, I would think to myself and quite often that oasis of calm in my day was a time to think of ideas. And I would count them on my fingers...you know, sometimes I'd have several ideas while I was swimming and l'd kind of think, 'I've got to write those down as soon as I get to a way of writing them down.' So I would count them and I'd go, 'OK, I've got four ideas, I've got to try and remember four ideas,' and when I came to write them down, I'd have to think, 'OK, what was the third idea? What was the fourth idea?'28

When the time comes to write down an idea, the physical act of getting it down on paper is important. Comedians tend to prefer writing their ideas longhand to word processing them, but even they themselves may be unaware of what motivates this preference. For example, Frank Skinner reveals that, '[A]II my stand-up gags are written free-hand. Everything else I write, sit-coms, sketches, this book, are written on a computer, but that just doesn't feel right with stand-up. I've never really worked out why. ${ }^{29}$ Jo Brand's account offers a clue as to why longhand might be preferred: 'I always have hundreds of half-filled little notebooks everywhere with scribbled ideas for jokes, or stuff I have read in the paper that I think would make good routines. Jokes tend to ferment in my head over a few days rather than present themselves on the page fully formed.' ${ }^{30}$

The word 'scribbling' is important here, suggesting both speed and a lack of finality. What Brand suggests is that ideas must be written down hastily, but without needing to be fully realised. What is written in her notebooks is provisional, the germ of an idea which will go 
on to 'ferment' into something which can be performed. It is also worth mentioning that the notebook is such a common tool of the stand-up trade that at least two comics have joked about them in their acts. What Marc Maron says about his notebook supports the idea that notebooks should be used for hastily scribbling:

I have my small, spiral notebook, these are cheap. [a couple of laughs] They're, I can get 'em for like five for a dollar ninety-nine at Costco and - I just, this is what I use, this is the way I work. Y'know, I cannot - I will, I will not buy a, a Moleskine notebook ever again. I can- I can't handle the pressure. [laughter] Have, have you ever bought a Moleskine notebook, I mean, you-you know they got the leather-bound, and there's a strap around 'em. I bought one once - and the second I scratched a word out in the Moleskine notebook, I was like, 'I fucked it up! [laughter] Got to throw it away!' [laughter]'31

For Maron, cheap notebooks are better than expensive Moleskine ones, because he does not want to feel that he cannot cross something out once he has inscribed it on the page. The point is that a comedian's notebook is a place for scribbling down and crossing out, rather than carefully inking in fully realised ideas. Even Andy de la Tour's fuller, less sketchy notes are full of crossings out and additions, with arrows showing where a thought begun on one line is continued on another.

Most of the ideas for the material in Break a Leg were originally written down in a notebook - ironically, a posh Moleskine one. However, the scratchy notes and primitive cartoons I scribbled onto its pages were deliberately rough, and in the podcast I reflected on why this roughness was important:

I don't like writing a script because if I write a script and then try and sort of learn it and perform it, it feels like I'm doing a play, and it feels inauthentic, and I can't get that kind of conversational style of delivery. It feels wrong... [A]s soon as you start typing something, it seems to give the words a greater sense of being sort of official and real. So it seems like you're actually writing a script somehow, even if you're making a note. Whereas if you scribble something down on paper, particularly because my handwriting is appalling, it doesn't seem to dignify it with being a thing yet, it's just an aide memoire for when I come back to actually start trying to prepare to perform it. ${ }^{32}$

The notes, then, remain rough to avoid being crystallised into a formal script. They are merely an 'aide memoire', with just enough inscribed onto the page to prevent the idea from disappearing. The jokes that comedians tell onstage about their notebooks make it clear that it is this fear of disappearance that makes them such important tools of the trade:

Mitch Hedberg: 'See I write jokes for a living, man. You know, I sit in my hotel at night, I think of something that's funny, then I go get a pen, and I write it down. Or, if the pen's too far away, I have to convince myself that what I thought of - ain't funny. [laughter, 7 seconds] ${ }^{33}$

Marc Maron: 'So I write these little ones, and if I write - you know, I can't read my writing really. And if I write and I can read it and it makes it over to the yellow pad, if I can read it there, maybe it'll - get out of my mouth. [a couple of laughs] But I write things in these impulsively. I have to have them at all times. I, here's something I wrote apparently on a plane. There was a baby, on the plane, that was crying at such an irritating pitch - if I 
met her as an adult I would still resent her. [laughter, 10 seconds] You gotta make sure you write that stuff down. [laughter] ${ }^{\prime 34}$

Both jokes express the anxiety of losing an idea. The potential joke must be written down in the notebook at the earliest opportunity to prevent its disappearance. With Hedberg, the tangential logic of his spaced-out persona makes him persuade himself that the idea is not worth walking across the room to get a pen. This laziness only becomes incongruously comic if we share the view that in not writing the idea down, he may be losing something important. With Maron, he lays bare some of his methodology as a way of framing the very good joke he gives as an example of the kind of thing he writes down in his notebook. Underlying this is the anxious neurosis of his stage persona, who writes 'impulsively' and has to have his notebooks 'at all times' so that he can 'write that stuff down.'

The point is to get down just enough information so that the idea will not be forgotten, and this means that what is written in a notebook will suggest a mere skeleton of the routine that will eventually be fleshed out in performance. There is a good example of this in the posh Moleskine notebook I used for Break a Leg, where I scrawled down ideas for a routine about Breaking Bad over two pages. The basic premise of the routine is that there are 'powerful parallels' between Walter White and me - both approaching 50, both struck down by a debilitating medical condition - but whereas he used his skills as a chemistry teacher to become a drug lord manufacturing crystal meth, I avoided that fate 'because it'd be quite hard to found an empire of crime based on my skills as a drama lecturer. [laughter]'.

The notes for this are messily written in pencil, with faint marks where words have been rubbed out with an eraser and arrows showing where clauses should be inserted or making links between different sections of the routine. What I have written is less cryptic and minimal than Linda Smith's notes, but not quite as fully spelled out as Andy de la Tour's. There are lines which never made it onto the stage, and others which would only be fully fleshed out in performance. For example, one note reads: 'Could sell Smarties and claim they're a powerful hallucinogenic drug.' There are two versions of how this idea might continue, the second of them being: 'a bunch of drama students jump out from behind a bush and use physical theatre techniques to simulate a psychedelic experience.'

Between writing this note and eventually performing it onstage, I developed the idea in various ways, making changes that were both small and large. A small change was that I shifted the word order about to put the comically significant phrase - 'physical theatre techniques' - at the end of the first line. A much larger change was that I expanded the idea by using instant character techniques ${ }^{35}$ to imagine how the drama students would go about their task: 
And at that moment - a bunch of drama students would run out from behind a bin - [laughter] and simulate a psychedelic experience using physical theatre techniques. [laughter] [manic fire mime] "WURRRR! I AM ETERNAL FLAAAME!" [swirling arms] "Look, I'm coalescing into swirly whirly patterns that fill your field of vision!" [laughter] [forming bunny ears with hands] "And I - am the White Rabbit! [laughter, 2 seconds] Come! Follow me down my rabbit hole into the vortex of your soul!" And on the end there's one who's not that bothered. [arms out either side, bored expression] [laughter] "I'm a tree?" [laughter and some applause, 4 seconds]

\section{Writing Break a Leg: the structuring stage}

Molineux concentrates on writing in terms of the individual gags and routines that make up an act, but does not consider the second stage of writing that happens when preparing for a new full-length show, which we might call the structuring stage. A five-minute guest spot or even a twenty minute set can be planned quite quickly, by simply writing out a set-list indicating the running order of the individual gags and routines. However, a full-length show requires careful structuring if it is to hold the audience's attention. Break a Leg would eventually run to 97 minutes in performance, and I knew that in order to sustain this length it would require a clear narrative, changes in tone and texture, and some kind of overall arc.

As recorded in the podcast, I initially tried to stick to analogue writing methods when I started sculpting the individual routines into a coherent and pleasing shape:

I planned my previous show on a computer and obviously it's easy to find your way around a computer, and it's easy to click and drag from one position into another. But my notebooks are...completely random and you can't click and drag something that you've scribbled onto a page. So what I've done is I've brought this marker pen here....and a bunch of A3 sheets. And I'm gonna start trying to sort of transfer ideas from the notebooks onto the $\mathrm{A} 3$ sheets and it might take lots of different versions of doing that before it starts to come together. ${ }^{36}$

However, this turned out to be a laborious process and didn't allow the kind of cutting and pasting made possible by word processing when pieces of material needed shifting around, so I ended up moving from notebook to laptop for the second stage of writing. As Molineux notes, the majority of comedians he surveyed preferred handwriting to document ideas for material 'but digital media were frequently cited as having organisational advantages.' ${ }^{37}$

Transferring handwritten notes from a variety of sources to a single Word document took an entire weekend, and I dedicated an entire episode of the podcast to reflecting on the process. ${ }^{38}$ The document I produced was over 8,000 words long, running to 27 pages in total. It was divided into ten sections, each with a clear heading and containing a number of individual sentences or paragraphs.

Planning the show in this way allowed me to take control of the raw material generated in the first stage of writing and shape it into something coherent. The sections allowed me to handle the overall flow of the narrative, to carefully guide the shifts in mood and tone, and 
to work out where the interval should be. They also allowed me to manage the information to serve the needs of particular jokes, for example establishing an idea which would be used in a gag later in the show, or planning the use of callbacks - a technique in which comedians refer back to an incongruity established in an earlier gag, often reintroducing it in a new context which makes it fresh and surprising.

The structure of the Word document visibly shaped the development of the show. For example, the section headings I used in the document were included as slides in the PowerPoint presentation that was projected behind me as I performed. These title slides were hand drawn with cartoon lettering then scanned and digitally projected, reflecting the blend of analogue and digital writing which I used to create the show. In the opening section - titled 'ADMIN' - I tell the audience, 'I'll talk you through the structure of the show', and go to a slide containing a list of the remaining section titles, reading each one out as I click to reveal it:

'ACCIDENT', started on that already. Er, then we'll have 'OPERATION', 'HOSPITAL WARD', 'MY FELLOW PATIENTS' and 'BOREDOM'. [laughter] Er, then, er, we'll have what for most people'll be the highlight of the show, 'INTERVAL'. [laughter] Er, followed by 'RECOVERY', 'BACK TO LIFE' and 'OLLY'S FINAL THOUGHTS', which is a bit like the end of The Jerry Springer Show. [laughter] You know, 'Jerry's Final Thoughts'. And then, finally, the 'ENCORE', now erm- [laughter, 3 seconds]

Having my ideas recorded in detail in a large Word document had the distinct advantage of allowing me to go back and amend it as my ideas developed. Sections could be cut or added, routines could be moved about, and I could amend the notes for a particular gag if I thought of a way of improving it. At this stage, the nature of my writing changed from being less like the short, cryptic notes of Linda Smith to being more like the full, longhand text of Andy de la Tour. This enabled me to develop the idea before starting to rehearse it, and to capture nuance and detail on paper to prevent it from disappearing.

However, as I noted in the podcast, there was also a distinct disadvantage: '[I]t looks more like an actual script than I've ever had for stand-up before, since I very first started doing stand-up. And the problem with that is I just cannot do that thing of sitting with a piece of paper and learning it.' I had to consciously avoid treating the document like a play text, which might risk making me lose my conversational delivery and short circuit the potential for spontaneity. At the end of my writing weekend I concluded: 'I'm not planning to say it verbatim, it's just it's my road map for a kind of oral version of what's written on that Word document. ${ }^{\prime 39}$

\section{Rehearsing Break a Leg}

Having generated the material and carefully structured it into a show, the next challenge was to learn the road map - to internalise all of the ideas contained in the 27-page 
document I had written so that I could speak them to an audience in a way that would sound convincingly conversational and spontaneous. I tackled this by rehearsing the show for several weeks, sometimes in studios at the University of Kent, and sometimes in a room in my house, and reflected on the process in a number of episodes of the podcast. More than once I talked about the sheer unpleasantness of rehearsing for this kind of performance: 'I don't like rehearsing stand-up at all...what I do is I write bullet points and then I put them on their feet by talking them through to myself. And it's a really, really embarrassing process. ${ }^{40}$

Many comedians avoid rehearsing their acts altogether. Twelve of the performers I interviewed for my book Getting the Joke directly addressed the subject of rehearsal, and eight of them (Al Murray, Mark Thomas, Shelley Berman, Jo Brand, Jeremy Hardy, Harry Hill, Dave Gorman, Mark Lamarr) said they never rehearse, although Brand and Hardy recalled that they had rehearsed for a short period when they first started in comedy. The remaining four (Rhys Darby, Milton Jones, Alexei Sayle, Alex Horne) said they did rehearse, but the form their rehearsals took varied and might amount to no more than sitting at a desk and speaking the words aloud.

Although this is a small sample, it does tend to suggest that the majority of comedians avoid the kind of rehearsal process that an actor would be familiar with. Instead they develop new material onstage in front of an audience. Some venues run regular new material nights in which established acts can try out freshly-written routines. Well-known comedians will sometimes appear unannounced in small comedy clubs to test new material. Alternatively, they might perform early versions of a new show in small venues and market them as a 'warm-up' or 'preview' gigs, to let the audience know that they are watching material which is still being developed. This sets the audience's expectation at a certain level and gives the comedian the freedom to explore without having to be totally slick and solid, as Harry Hill explains:

I can do 40 minutes, and basically, the rules of engagement are that the audience know I'm floundering around trying to find out what's funny, so they give me a lot more rope. You know, a lot more leeway. And I can really get a lot out of it quite quickly, really. Or at least I can, you know, whittle it down. ${ }^{41}$

The main advantage of rehearsing in public in this way is that, as Al Murray puts it: '[U]ntil it's in front of an audience and you've got that energy...you know, the energy between you, of the audience and the performer, you don't really know if it's good. You just don't really know if it's ever going to work'. ${ }^{42}$ The audience's responses show the comedian how to develop the material. If something gets a laugh, it can be kept and possibly developed. If something fails to get a laugh it must be changed or dropped.

However, in spite of this fundamental advantage, I chose to rehearse Break a Leg in private, explaining the reasons for this in the opening 'ADMIN' section of the show: 
When big comedians do a big show like this, when proper comedians do it, right, they do preview shows for weeks or months first, trying out the material with audiences, right. Erm - but I don't have the kind of following which would allow me to do a shit version of the show first. [laughter] I - I've just got you. Right? [laughter] And thanks for coming. But you know, you're not gonna come more than once, that's my point, right? So, er - all I'm saying is we're gonna be finding out, me and you, at the exact same time, whether this stuff is funny or not. [laughter] Which is quite exciting - or it could be a long night for everyone. [laughter]

Rehearsing stand-up in private is a very peculiar experience. In a 1990 documentary, the veteran variety comic Frankie Howerd confesses:

The thing about learning words, it's the most difficult part of your job. I find it very difficult to sit still and learn words, I have to keep on the move, I don't know why. First of all, I'm claustrophobic. Sometimes, there's some fields near where I live and I go out in a field if there's nobody about - and I can shout again and project the voice. $^{43}$

The programme then cuts to footage of Howerd reading through a script in a field, surrounded by cows. It is a consciously whimsical scene, which highlights the oddness of rehearsing stand-up comedy, in which there is an extremely stark contrast between the situations of rehearsal and performance.

Stand-up comedy is an extremely social form of performance. It often takes place in pubs, bars, restaurants, or dedicated comedy clubs. Here, the audience may sit around tables and enjoy alcoholic drinks while they watch the show, making the experience feel as much like a night out with friends as a show. Even when it is performed in theatres with the audience formally seated in an auditorium - as Break a Leg was - it feels like a social exchange between performer and audience. As Ian Brodie pointed out, stand-up is 'dialogic form, performed not to but with an audience. ${ }^{44}$ The comic seeks the responses of the audience as a whole, in the form of laughter, applause and other coordinated responses. He or she may also interact with individual punters, in the form of question-and-answer sessions, impromptu conversation and exchanges with hecklers. Stand-up is intensely public, allowing the comedian to share his or her view of the world with tens, hundreds or even thousands of people at once.

By contrast, rehearsing stand-up is an abnormally asocial experience. This is what makes the image of Frankie Howerd reciting his script while surrounded by a field of cows so whimsical. Talking to oneself is popularly acknowledged as a sign of madness, and more than one comedian has admitted to being afraid of somebody witnessing their private rehearsals and thinking them crazy. The variety comic Ted Ray openly confessed this when he recalled rehearsing into a mirror for his metropolitan debut at the London Music Hall in Shoreditch in 1930: 'This may sound rather ridiculous and I have no doubt that had anybody happened to see me they would have thought I had gone off my head'. ${ }^{45}$ More recently, Andy de la Tour - who would rehearse new material both when he was a key figure in the 
early alternative comedy scene, and in a recent brief return to stand-up on a trip to New York - remembers not being able to rehearse in front of his partner while they were staying in a friend's New York flat: 'I had to wait for Susi to go off somewhere on her own - no way was I going to be standing in Melanie's front room practising my set with her listening in from the other room thinking to herself, what is he talking about?'46

One of the main difficulties of speaking comedy material out loud alone in a room is that, as Al Murray pointed out, without an audience there is no 'energy'. As I noted in Getting the Joke, there is an 'exchange of energy between performer and audience' in stand-up, in which the comedian 'is filled with the energy that he or she gets from the audience's responses'. Without this 'there will be nothing to fuel their performance'. ${ }^{47}$

The yawning silence created by the absence of an audience can produce enormous selfdoubt. Andy de la Tour describes how this feels: 'It's weird, because as you're doing it, you think, "This is staggeringly unfunny...Who would even dream of laughing at this kind of stuff?" And you just have to have confidence that when you first thought of it, it made you smile, made you laugh. ${ }^{48}$ I made a similar point in the podcast, tracing the emotional shift from the excitement when the idea first appears to the awful doubt of the rehearsal process:

Even though, when I was writing this, every time I wrote something in my notebook I'd be going, "Oh yeah, that's going to be brilliant!", actually speaking it through so that I can get it into my head is tortuous! Because it's making me go, 'Well, that's not very funny. And that's not very funny.' It's like I'm imagining that there's an actual audience there but they're sitting there in appalled silence. ${ }^{49}$

Moreover, there is the danger that in rehearsing alone, the wording might become too fixed and inflexible, leading to a performance which - to reverse Mark Thomas's definition - is more of a recital than an encounter. In the podcast, I reflected on the potential problems caused by speaking the words alone rather than to somebody else:

A lot of ideas in this show came from things I've said to people. And in some cases, that I've said repeatedly to different people and they've always kind of got a laugh. But there's something about saying something to an actual person rather than saying it to an empty room that makes you be able to formulate it in the right way. And I suppose one of the things I worry about is by repeatedly saying it to an empty room, I might be making the wrong way of saying it fixed and concrete. So that it precludes me from saying it the way that instinct would tell me to say it if I was talking to a real person, or indeed a real audience. ${ }^{50}$

Given the potential drawbacks of rehearsing stand-up, it might seem as if there is no real reason for doing it. However, Andy de la Tour uses some revealing language in describing the general unpleasantness of rehearsing alone: ' $[Y]$ ou have to just remind yourself that this is eating your greens, this is doing your homework' ${ }^{51}$ Both of these - eating greens and doing homework - are things that are generally considered unpleasant but necessary, 
eventually yielding benefits for those that can bear to do them. So what are the benefits of rehearsing stand-up?

One advantage that I identified in the podcast is that, ' $[Y]$ ou hear about people who do previews and they do the first preview and it's four hours [long] or whatever...When standup just exists in ideas form, before it's actually been embodied and enacted in the process of performance, you don't really have a solid idea of how long a bit's going to be, until you've actually done it. ${ }^{52}$ Rehearsing the material in private means that it can be cut down to a reasonable length before being inflicted on the public. Knowing how long the material was likely to take to deliver encouraged greater economy, and allowed me to cut out some weaker sections - even if I only had my own comic instincts to guide me, rather than the more reliable responses of an audience in a preview gig.

More importantly though, speaking the words through to myself in a room or a studio allowed me to play with the ideas verbally, to explore the particular form of words I might use to articulate them, and to find the appropriate comic rhythms within the sentences I would speak:

I think there is a value to rehearsing actually, which is that if you've said the words out loud...I think the advantage is that you can get a kind of verbal articulacy which counts for a lot. And it's almost like you have to kind of internalise the key phrases so that they just trip off the tongue. 'Cos you can kill a joke by tripping over one syllable of a word. And sometimes where the joke lives is in the specific rhythm and metre of your delivery. ${ }^{53}$

Andy de la Tour makes a similar point, likening the internalising of comic rhythms in rehearsal to the finessing of physical skills in sports training:

The only way I could do it was to kind of rehearse it, to myself, in my front room...I would have to say the stuff out loud, l'd have to hear it out loud to see the rhythm of something. Because as you know about comedy, you're not giving a lecture, you're not having a conversation, you're actually trying to make people laugh. So the rhythms of it are critical....if you don't know it well enough, you're not going to get the rhythms right and then they won't laugh. So you just have to...practice. A bit like I imagine being a snooker professional. You've got your table and your cue, you know. And you've got to hit the balls all day and there's nobody watching. But you've got to do it...so when you do it in front of the audience, you know, in front of a crowd, you can do it. ${ }^{54}$

Again, this is revealing. For de la Tour, like the snooker player practicing shots to develop the physical skills needed in a match, the comedian rehearses in private to find the verbal rhythms needed in performance.

The laboriousness, difficulty and self-doubt of the rehearsal process bears a strong resemblance to what the American comedy writer Norman Lear revealed of his working life in interviews conducted by the psychologists William F Fry and Melanie Allen in the 1970s. ${ }^{55}$ Like a rehearsing comedian, Lear confessed to talking aloud to himself whilst he wrote: 'You 
talk - when you're actually working on the script. You get yourself on a tape recorder. ${ }^{56} \mathrm{He}$ identifies a 'long, long period' in the writing process which 'seems endless' which he calls 'shit in the head'. This period is dispiriting and enervating: 'I'm afraid nothing is going to come through this morass, nothing is going to escape or break through, and I can't motivate myself to do anything, least of all write, but I feel like I should be writing every second of it. ${ }^{57}$ However, the 'shit in the head' period is followed by:

a wonderful period... which could last for a week or a month, when everything is going so well it's just, well, the only way to describe it is one extended orgasm...everything is gushing, everything is just gushing... When the muse is with you; once you're at this point, you just keep going and going, all the difficult problems are behind you. ${ }^{58}$

What Lear describes seems to map directly onto the process of rehearsing and performing stand-up. For him the move from toil and creative blockage to flow and fluidity relates to two different phases of the writing process, rather than the transition from rehearsal to performance. In stand-up comedy, the entire rehearsal process is like Lear's 'shit in the head' phase, a struggle with demotivation and self-doubt in the face of the lack of any validation from an audience. The point of it is to prepare the comedian so that the performance itself can become a 'wonderful period' of articulacy and control in which 'everything is just gushing'.

\section{The creation of new art}

Matthew Reason's argument that the impulse to document performance is to prevent the disappearance of 'existing art' is turned on its head by the kind of documentation which stand-up comedians produce. Reason claims that the 'primary preoccupation' is 'not the creation of new art but ensuring the documentation of existing art.' By contrast, as Molineux points out, the stand-up comedian 'self-documents in order to facilitate memory in performance. ${ }^{59}$ The scribbling of ideas into notebooks or scraps of paper, or the creation of Word documents planning out the arc of a full-length show are an inherent part of the creative process, with the emphasis firmly on the creation of new art.

Even when comedians make their own private audio or video recordings of their performances, these are used to hone and develop material for future performances. The very notion of existing art is, in a sense, misleading in relation to stand-up comedy, because the material will often change and develop over time, evolving from show to show in response to audience reaction. As Canadian comedian John Wing puts it, 'a bit is never finished' ${ }^{60}$

However, Reason's assertion that documentation is driven by the fear of disappearance holds true for stand-up, albeit with a different emphasis. The fear is not so much that a completed, perfected show will disappear once it has been performed, but instead that the 
seeds of a future performance might disappear before they have a chance to bloom. The emotional attachment that comedians feel towards their notebooks, and the jokes they tell about them onstage, are tangible symptoms of the fear that an idea might disappear before it is given a chance to take form onstage. The importance of the British Stand-Up Comedy Archive is that by collecting examples of the documentation that comedians produce, it can help us to shed light on their working processes - which have traditionally received so little attention that even the comics themselves can claim to not have a methodology.

In the moment of performance, what the audience see is just the tip of the iceberg. The frantic jotting down of ideas, the reworking and refining, the onerous hours of rehearsing alone in a room, the preview shows, the listening back to tapes of the last performance to prepare for the next, and the sheer weight of performing experience are all hidden beneath the surface. All that is on show is the apparently informal conversation being conducted by a comedian who is working hard to hide the graft and toil that has allowed him or her to come across as being so natural and spontaneous. Of course, none of that hard work can guarantee that the comic will shine in performance and forge a warm, vibrant interaction with the audience, thus yielding the necessary laughter - but the careful process of documentation and rehearsal is the best way of inviting inspiration onto the stage.

\footnotetext{
${ }^{1}$ Andy de la Tour, interview with Oliver Double, National Theatre, 10 February 2016. It is worth mentioning that Alexei Sayle does remember discussing the ethical and technical aspects of stand-up with Andy de la Tour and Tony Allen (see Oliver Double, Getting the Joke: The Inner Workings of Stand-Up Comedy, London \& New York: Bloomsbury, 2014, p.4).

2 Born Standing Up: A Comic's Life, London: Pocket Books, 2007.

${ }^{3}$ How I Escaped My Certain Fate: The Life and Deaths of a Stand-Up Comedian, London: Faber and Faber, 2010; and The 'If You Prefer a Milder Comedian, Please Ask for One' EP, London: Faber and Faber, 2012.

${ }^{4}$ Stuart Goldsmith, The Comedian's Comedian Podcast, episode 1, 19 March 2012.

${ }^{5}$ Christopher Molineux, 'Life memory archive translation performance memory archive life: textual selfdocumentation in stand-up comedy', Comedy Studies, vol. 7, no. 1, 2016, pp.2-12; p.2.

${ }^{6}$ https://www.kent.ac.uk/library/specialcollections/standupcomedy/index.html, accessed 22/07/16.

${ }^{7}$ A video recording of the show is available on YouTube: https://www.youtube.com/watch?v=rel7wNujQkQ

${ }^{8}$ Robin Nelson, Practice as Research in the Arts, Houndmills \& New York: Palgrave Macmillan, 2013, p.37.

${ }^{9}$ Sharon Lockyer, Brett Mills and Louise Peacock, 'Analysing stand-up comedy', Comedy Studies, vol. 2, no.2, 2011, pp.99-100; p.99.
} 
${ }^{10}$ Comedy Studies, Vol. 2 No.2, 2011. See, respectively: Roberta Mock (2011), 'Really Jewish? Joan Rivers Live at the Apollo', pp. 101-111; Sharon Lockyer, 'From toothpick legs to dropping vaginas: gender and sexuality in Joan Rivers' stand-up comedy performance', pp.113-23; Louise Peacock, 'Joan Rivers - Reading the meaning', pp.125-37; Brett Mills, “'A pleasure working with you”: Humour theory and Joan Rivers', pp.151-60.

${ }^{11}$ Nelson, p.30.

12 Matthew Reason, Documentation, Disappearance and the Representation of Live Performance, Houndmills, Basingstoke: Palgrave Macmillan, 2006, pp.1, 16.

${ }^{13}$ Reason, pp.16-17.

${ }^{14}$ Reason, pp.35-37.

${ }^{15}$ Reason, p.57.

${ }^{16}$ Molineux, p.5.

17 Double 2014, p.325.

18 Mark Thomas, The Linda Smith Lecture, Gulbenkian Theatre, Canterbury, 12 May 2015.

${ }^{19}$ Molineux, p.4.

${ }^{20}$ Unpublished page of performance notes deposited in the British Stand-Up Comedy Archive, catalogue number BSUCA-LS-003-016-001-007-10-A.

${ }^{21}$ Unpublished audio cassette recording deposited in the British Stand-Up Comedy Archive, catalogue number BSUCA-LS-009-002-027-001A-A.

${ }^{22}$ Andy de la Tour, interview with Oliver Double.

${ }^{23}$ Unpublished page of performance notes deposited in the British Stand-Up Comedy Archive, catalogue number BSUCA-AT-002-004-001-1-M.

${ }^{24}$ Unpublished audio cassette recording deposited in the British Stand-Up Comedy Archive, catalogue number BSUCA-AT-001-001A-A.

${ }^{25}$ Molineux, p.3.

${ }^{26}$ Jo Brand, Can't Stand Up For Sitting Down, London: Headline Review, 2011, p.86.

27 Molineux, p.3.

28 Oliver Double, Breaking a Leg, episode 18: 'After the Show', 13 December 2015.

${ }^{29}$ Frank Skinner, Frank Skinner, London: Century, 2001, p.288.

${ }^{30}$ Brand, pp.86-87.

${ }^{31}$ Marc Maron, This HAS to be Funny, USA: Comedy Central Records, 2011.

${ }^{32}$ Breaking a Leg, episode 3: 'Notebook', 7 September 2015.

${ }^{33}$ Mitch Hedberg, Mitch All Together, USA: Comedy Central Records, 2003.

34 This HAS to be Funny.

${ }^{35}$ See Double 2014, chapter 24.

${ }^{36}$ Breaking a Leg, episode 6: 'First Rehearsal', 30 September 2015.

${ }^{37}$ Molineux, p.11.

${ }^{38}$ Breaking a Leg, episode 9: 'Writing Weekend', 2 November 2015.

${ }^{39}$ Breaking a Leg, episode 9.

${ }^{40}$ Breaking a Leg, episode 6.

${ }^{41}$ Harry Hill, interview with Oliver Double, by telephone, 26 August 2004.

${ }^{42}$ Al Murray, interview with Oliver Double, by telephone, 2 April 2012.

${ }^{43}$ Arena: 'Oooh er Missus! The Frankie Howerd Story', BBC2, 1 June 1990.

${ }^{44}$ Ian Brodie, 'Stand-up Comedy as a Genre of Intimacy', Ethnologies, vol.30, no. 2, 2008, pp.153-80; p.154.

45 Ted Ray, Raising the Laughs, London: Werner Laurie, 1952, p.69.

${ }^{46}$ Andy de la Tour, Stand-Up or Die, London: Oberon Books, 2013, p.45.

${ }^{47}$ Double 2014, pp.188-89.

${ }^{48}$ Andy de la Tour, interview with Oliver Double.

${ }^{49}$ Breaking a Leg, episode 12: 'Why Document?', 10 November 2015.

${ }^{50}$ Breaking a Leg, episode 12.

${ }^{51}$ Andy de la Tour, interview with Oliver Double.

52 Breaking a Leg, episode 12.

${ }^{53}$ Breaking a Leg, episode 6.

${ }^{54}$ Andy de la Tour, interview with Oliver Double.

${ }^{55}$ William F Fry \& Melanie Allen: Make 'Em Laugh: Life Studies of Comedy Writers, Palo Alto, California: Science \& Behaviour Books, 1975; and 'Humour as a Creative Experience: The Development of a Hollywood Humorist' in Antony J Chapman \& High C Foot (eds.), Humour and Laughter: Theory, Research and Applications, London: 
Wiley, 1976, pp.245-58. Lear is anonymised as 'Nathan' in the chapter 'Humour as a Creative Experience', but is identified as Norman Lear in the book Make 'Em Laugh.

${ }^{56}$ Fry \& Allen 1975, p.33.

${ }^{57}$ Fry \& Allen 1976, p.255.

${ }^{58}$ Fry \& Allen 1976, p.256.

59 Molineux, p.8.

${ }^{60}$ Quoted in Molineux, p.5. 